HOW, a Colombian Journal of Teachers of English. No. 2. (pp. 54-60). (ISSN: 0120-5927). 1997.

APA citation style: Benavides B., Jorge E. (1997). The Educational Context of Computer-assisted Language Learning (CALL). HOW, a Colombian Journal of Teachers of English) (2), 54-60.

\title{
The Educational Context of Computer-assisted Language Learning (CALL)
}

\author{
Jorge E. Benavides B. (joelbebu@gmail.com) \\ Departamento de Lingüística e Idiomas \\ Universidad de Nariño, San Juan de Pasto, Colombia
}

\section{Information technology in Education}

It is very common for many people to experience a great deal of excitement generated by rapid new technological developments and the ongoing need to think about how to fit this into existing systems. For the most part, this has resulted in a situation where almost all the energy is concentrated on the actual technology itself and not on the implications of its use. The resulting danger is that it is easy to be misled by the whole business and to become uncritically enthusiastic about future possibilities. It is important, then, to concentrate on the real purpose of using new technology so that quite a considerable investment of time, energy, enthusiasm and resources is worth the effort.

The overall effect which information technology is having on society at large cannot be denied, and schools, whether they wish to or not, will have to become involved. Today, only a comparatively small proportion of teachers and schools are using the technology in an extended way. However, it is still very early to show significant or dramatic changes since the current situation cannot be taken as anything other than an initial stage. However, the impact on individual schools and individual practitioners, where the innovation has been made available, is said to be significant.

\section{The Introduction of Computers in Education}

The introduction of computers in education started during the early sixties as ComputerBased Learning ( $\mathrm{CBL}$ ), a fast growing method of instruction which is about using a computer to learn about something, and which may previously have been taught by more traditional methods. This included books, tapes, slides, and of course, human teachers. CBL's initial concept was to use computers as some sort of teaching aid.

For many educationalists, $C B L$ began at a most unfortunate time in the history of computing. It started when computers were all of the type that filled very large rooms and had extremely specialized experts to whom most people asked for assistance, educators and teachers included. The introduction of $\mathrm{CBL}$ in education has been slow and inconsistent because it was originally developed as a method of programmed instruction (PI) and programmed learning (PL) related to the work done by behavioral psychologists such as Skinner, Crowder and Pressey. Skinner's method was essentially a linear series of small learning steps, whereas Crowder advocated a branching approach involving a multi- 
HOW, a Colombian Journal of Teachers of English. No. 2. (pp. 54-60). (ISSN: 0120-5927). 1997.

choice question format. Each methodology was encapsulated into self-instructional 'Programmed Learning' text books where the reader was directed to different sections depending on the answer given to a question.

Later, it was realized that the computer offered a more flexible presentation capacity which, combined with the American enthusiasm for technology, led many educators in the 1960's to produce CBL in the form of thousands of pages of text with questions of the form 'which is correct: 1, 2, or 3?' This type of CBL was called Computer-Assisted Instruction. Fortunately for many teachers, this method was a failure and the teachers who thought that the computer might do them out of their jobs could breathe again.

\section{Computer-Assisted language learning}

Computer-Assisted Language Learning (CALL), in very general terms may be understood as the concept of using computers for language learning purposes or as a system in which computers are used as supplementary tools for language learning (Benavides, 1989, 1993). We can say that CALL started as a part of the PLATO educational project in the USA, at the University of Illinois, one of the best known and most ambitious educational projects which started in the 60's using very expensive mainframe computers. In England CALL projects initiated during the 70's, one of which started at University of Hull.

During the 70's, with the arrival of affordable microcomputers there were many successful attempts to introduce CALL in private and public educational institutions even though the hardware development was far ahead of the amount and quality of the software available. The microcomputer boom in the 70's and 80's led many institutions to buy microcomputers without giving serious planning to what they wanted to do with these machines. This uncontrolled enthusiasm was the rule in most developed countries regarding the use of this new tool. To this day we have learned that uncontrolled enthusiasm in technology investment is not enough for achieving educational goals and the introduction of computers in language learning has to be taken more pragmatically.

CALL has undergone quite different stages since the introduction of computers in language teaching and progressively into language learning. Since its beginnings, CALL has struggled to accommodate to the contextual situation, that is, to progressively match its technology with current methodology practices. In its beginnings, CALL was relegated to mechanical and routine aspects of language teaching. Drill and practice was usual during the seventies and eighties. However, a more communicative approach to CALL was indeed sought.

Today CALL is involved in more communicative activities and the interaction usercomputer, user-user is said to be far more advantageous in terms of production and more cognitively demanding. However, CALL has reached a stage in which people are trying to find a pedagogically sound scheme to account for the different processes which can be achieved or set up by a computer, computer-based materials and consequently by 
HOW, a Colombian Journal of Teachers of English. No. 2. (pp. 54-60). (ISSN: 0120-5927). 1997.

different learning scenarios. In other words, we need to start establishing a supportive pedagogy which does not necessarily relate to current methodological theory. Often times CALL activities, software, the machine itself, not to mention the interaction achieved within a CALL environment have been questioned in terms of its pedagogical value. Nonetheless, there has been a lot of effort to introduce, master, and filter the new technology in educational contexts with promising results and this is sometimes disregarded by most critics, or technophobic educationalists.

As Phillips (1985), and Weible (1987), (mentioned in Hubbard, 1992) put it, CALL and its technology has been striving and searching for an appropriate and effective methodology. Through its different stages, CALL has been being established as a stand-alone discipline, and abundant literature supports the need for a methodological framework for CALL. Consequently, several efforts have been made in order to achieve this goal. Higgins (1983, 1988), Underwood (1988), Phillips (1985), and Wyatt (1987), to mention just a few, and lately Hubbard, 1992 have come up with some ideas of how a methodological framework for CALL can be established in the domain of courseware and materials development.

Using the experience of the people engaged in the development of CALL, its effectiveness, advantages, disadvantages, limitations, capabilities through the approximately two decades of its permanence in language teaching and language learning, it is possible to suggest a general view of CALL into a more identifiable type of 'method' in language teaching and learning. In this way we will be looking forward to making CALL not only revolutionary but also evolutionary. Some important features related to language learning using a CALL system can be briefly analyzed in order to get the idea of change and innovation.

\subsection{Exploratory and discovery learning through CALL}

Learners can make discoveries about the language being learned especially in CALL activities (i.e. text reconstruction activities) in which they have to test their intuitions about how the language works. According to Stevens, (1992) students working in CALL are more likely to internalize the fruits of their own discoveries. This, so called, exploratory approach provides students with powerful means of accessing linguistic data, broadening the scope of action in any field, allowing and promoting students' curiosity and independence.

The exploratory learning materials cover authentic texts as in a 'concordancing' program in which occurrences of a given word or expression can be found in texts, to systematically offer insights of how language works in the case of grammar and vocabulary learning, for example. One of the best examples of exploratory interaction is hypermedia of which hypertext is one application. In hypertext the possibilities of accessing information in a non-linear form are vast, thereby broadening the possibilities for exploratory and discovery learning. This is the principle of navigating through information in the Internet and the World Wide Web. This type of text can be combined with videos and sound, 
HOW, a Colombian Journal of Teachers of English. No. 2. (pp. 54-60). (ISSN: 0120-5927). 1997.

dictionaries, encyclopedias, diagrams, maps, atlases, etc. resulting in a multimedia domain which the students can explore to retrieve the information needed for a particular topic or unknown word, for example.

With this type of exploratory approach to language learning in CALL, the students have to undergo an introductory stage in which they are guided to the use of different types of programs emphasizing this particular characteristic. Systematic guidance at early stages can lead to another area in the educational process within a CALL context, that is, learner autonomy and learner independence.

\subsection{Collaborative learning through CALL}

In the Vygotskyan view of learning, the teacher's role is that of a supporter and his communicative role with learners has to be emphasized. This brings to CALL the question of whether teacher-learner interaction or learner-learner interaction is preferred for cognitive and learning purposes.

Research indicates that learners working in groups with computers can address problemsolving tasks in a more comprehensive way since the explicit sharing of ideas is what makes a group work towards a solution. Light's (1993) review of qualitative and quantitative research in the field shows that teachers perhaps have to re-evaluate their own work if their job is to make learning more dependent on learners' interaction. This leads us to think that collaborative learning embodies the social component sought by Vygotsky and the emphasis on group work when using computers, especially at early stages in the process.

Within the behaviorist theory of learning, learners are considered as the ones who achieve a desired competence and performance. In CALL, individualization could be interpreted as a form of self- instruction conducive to 'effective learning'. Even with the constructivist approach to language learning in mind, the learner could be seen as an individual trying to build models of the world (knowledge) based on previous experiences. This could lead to a strong form of user-machine dependence, with the frightening idea of a CALL scenario where there could be something like one computer per student where the learner will almost always spend most of the time in front of the machine without interacting with others (teachers and learners included).

This is probably one the factors and arguments raised by opposers to the use of computers in education due to this dehumanizing characteristic, and no doubt it would be a big mistake, to see the role of the computer as that of the teacher, thereby replacing the latter from the educational context. The learning process, especially in language learning is as much a social as an individual process. The possibility of using computers to provide context for language learning might be one of the key areas for CALL in which the teacher often failed (to provide the kind of teaching geared towards what the student needs as an individual). However, the computer is said to provide the scenario for small group work. 
HOW, a Colombian Journal of Teachers of English. No. 2. (pp. 54-60). (ISSN: 0120-5927). 1997.

Before the arrival of computers this aspect has been difficult to achieve in practice, as some reports may inform. In primary classrooms, for example, Galton, (1980) reports that despite being seated in groups, children almost always worked separately, that is, on their own tasks.

Studies such as those by Jackson, Fletcher, and Messer, (1986) have reported that in primary schools the predominant pattern was children working in pairs rather than individually with the computer. Children are often engaged in a truly joint venture working together on a shared task. However, people tend to see or imagine a child or an adolescent working alone over his computer for long periods of time. On the contrary, evidence tends to show, at least at initial stages, that computers may be well associated with collaborative learning.

Another wrong idea about the use of computers for improving learning arises from the very fact that teachers who are said to be concerned with the social aspects of learning, in the end, only seek and praise individual performances in classrooms and individual outcomes. Unfortunately, this is a generalized concept in education: one thing is the way collaborative learning is conceptualized, and the other is how it is realized or put into practice.

Other studies such as those of Light and Glachan (1985) have shown that simply putting learners together in front of a computer is not a guarantee of peer facilitation in their learning process. There has to be a condition in the learning situation, and that has to do with the engagement of the learners in the task. As suggested by Light (1993) it might be just the fact of having to talk about what the student is doing as he solves a task which makes learning more effective.

Perhaps, the most striking evidence in favor of collaborative learning may be found in the study by Johnson, Johnson and Stane, (1986) (mentioned in Light, 1993) where three groups of 11-13 year-olds worked on a geographic simulation task. The first, working individually, the second competitively and the third cooperatively. Results showed that the third group displayed a significantly higher level of achievement on a day-by-day basis and on a final test. Also, they showed less dependence on the teacher and more positive attitudes towards working with students of the opposite sex. Based on these initial findings, we can say that collaborative groupings could play a central role in CALL. Evidence of social-cognitive conflict was also found in works like those of Light and Glachan, (1985) where the number of conflicts (disagreement about strategy and argument) of twenty pairs of 8 year-olds working with 'mastermind', a computer game based on a code-breaking peg board were found to be decisive in a significantly better performance of subjects on a test. This evidence is then consistent with the idea that conflict offers a productive learning experience. 
HOW, a Colombian Journal of Teachers of English. No. 2. (pp. 54-60). (ISSN: 0120-5927). 1997.

The advantages of having a partner working at a computer, according to Light (1993) relies on the fact that this may be perceived by learners as being more fun and less threatening, they would pick up ideas from one another and help each other to remember things. Discussion and hypothesis testing are also relevant in working in small groups with the computer. The saying that goes 'two heads think better than one' can be applied here in terms of 'two heads learn better than one'.

\subsection{CALL within a self-access system}

The idea of free-learning (open-ended learning) is a very powerful one since in the realm of CALL it can cope with a large variety of learning possibilities. The autonomous user is free to choose his own course, topics, and work at his own pace. However, in this approach, high motivation may not necessarily mean learning efficiently. The student may not be very good at selecting his own learning strategy, especially at initial stages. This problem could be alleviated if the introduction to self-access learning, learner autonomy, and flexible learning is done in a process where the learner is being trained to progressively go from an externally-directed-learning approach to a self-directed learning one.

Another way of solving the problem for achieving autonomous learning could be to use a self-access system where the students can choose tasks and activities without these necessarily having been assigned by the teacher. This would lead to a more flexible way of learning, in which learning contexts have to be made appropriate to the students' individual needs, (provided there are the facilities, resources, materials and guidance available and organized in a resource center).

Thus, the learners will be involved in meaningful tasks, problem solving, decision making, etc. thereby promoting their responsibility for their own learning. This process by no means underestimates the role of the teacher. In the end, the ideal learner would be the one who at any stage in the process of education is less dependent on the teacher to sort out his own learning challenges. Similarly, the ideal teacher would be the one who after his gradual and progressive guidance can see the learner at later stages of his educational process as an independent, responsible, and self-confident learner.

We can see a self-access system in language learning to be more associated with the Vygotskyan view of learning rather than with the behavioristic approach. In the behavioristic operant-conditioning approach teaching is central, whereas for the constructivists and Vygotskyans learning is central, and teaching is only a vehicle for creating the conditions and contents for the learners, in what Jones \& Mercer, (1993) call 'self-motivated, self-directed learning'. In other words, directed learning can be considered harmful in that it is not necessarily based on the learner's understanding. 
HOW, a Colombian Journal of Teachers of English. No. 2. (pp. 54-60). (ISSN: 0120-5927). 1997.

\section{References}

Benavides B., Jorge E. (1993). Informática Educativa para el Aprendizaje de los Idiomas. Revista de Investigaciones Vol. 6, No.1. Pasto, Universidad de Nariño.

Benavides B., Jorge E. (1989). Iniciación a la Instrucción Complementaria del Inglés Mediante Computadores. Revista de Investigaciones. Año 3. No. 5 Vol. III. Pasto. Universidad de Nariño.

Galton, M. (1989). Teaching in the Primary School. London: David Fulton Publishers.

Hubbard, P. (1992). A Methodological Framework for CALL: Courseware Development. In M. Pennington, \& V. Stevens. (Eds.) Computers in Applied Linguistics. Clevedon: Multilingual Matters Ltd.

Jackson, A., Fletcher, B. and Messer, D. (1986). A survey of microcomputer use and provision in primary schools, Journal of Computer Assisted Learning, 2: 45-55.

Johnson, R., Johnson, D. and Stanne, M. (1986). Comparison of computer-assisted cooperative, competitive and individualistic learning. American Educational Research Journal, 23: 382-92.

Jones, A. \& N. Mercer. (1993). Theories of Learning and Information Technology. In P. Crimshaw. (Ed.) Language, classrooms and computers. London: Routledge.

Light, P. (1993). Collaborative Learning with Computers. In P. Crimshaw. (Ed.) Language classrooms and computers. London: Routledge.

Light, P. R. \& Glachan, M. (1985). Facilitation of individual problem solving through peer interaction, Educational Psychology, 5: 217-25.

McDonough, J. \& Shaw, C. (1993). Materials and Methods in ELT: A teachers Guide. Cambridge, Massachusetts: Blackwell.

Philips, M. (1985). Logical possibilities and classroom scenarios for the development of CALL. In C. Brumfit, M. Philips \& P. Skehan (Eds.) Computers in English Language Teaching. New York: Pergamon.

Stevens, V. (1992). Humanism and CALL: A coming of Age. In M. Pennington, \& V. Stevens. (Eds.). Computers in Applied Linguistics. Clevedon: Multilingual Matters Ltd.

Underwood, J. Computers Teacher: (1984). Linguistics, Computers and the Language Teacher: A Communicative Approach. Rowley, MA: Newbury House.

Weible, D. (1987). Towards a Media-specific methodology for CALL. In W. Flint Smith (Ed.), Modern Media in Foreign Language Education: Theory and Implementation. Lincolnwood, IL: National Textbook Company.

Vyatt, D. (1983). Three major approaches to developing computer-assisted language learning materials for microcomputers. CALICO Journal, 1: 2, 34-38. 